\title{
PRUEBA INICIA Y VULNERABILIDAD DE COLEGIOS: LA OTRA SEGREGACIÓN
}

por Stephanie Gutiérrez, estudiante de Ingeniería Comercial UAH

Eugenio Giolito, Académico FEN UAH. Ph.D. en Economía, Universidad de Maryland, Estados Unidos

Oe

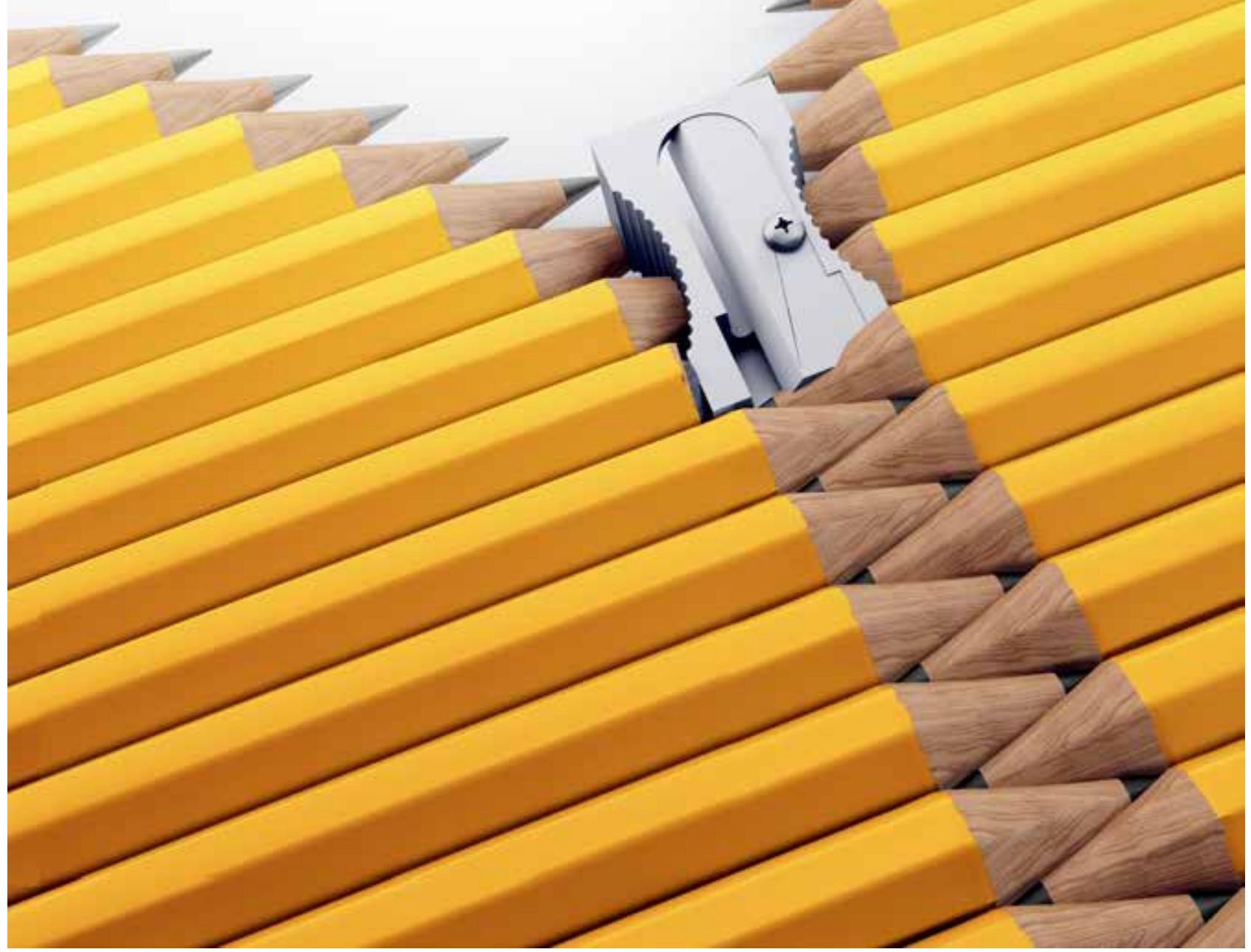


Si bien la segregación escolar en Chile es un tema recurrente en la agenda pública, generalmente se hace un mayor hincapié en la selección de los alumnos y la falta de "mezcla" entre estudiantes de distintos niveles socioeconómicos. Sin soslayar la importancia del tema, si la educación que reciben los estudiantes fuera de una calidad similar, el efecto de dicha segregación se limitaría a la falta de interacción entre grupos y a las pocas redes de acceso laborales (que en nuestro caso suelen ser relevantes) a las que pueden acceder. Sin embargo, la calidad de la educación que reciben los alumnos más vulnerables, concretamente al nivel formativo de los profesores es un tema menos difundido y del que queremos referirnos en este artículo. Para ello, nos centraremos en los resultados de la prueba Inicia, rendida por los egresados de pedagogía que cruzamos con información del colegio que termina empleando a dichos egresados.

La Prueba Inicia es una evaluación de carácter voluntario aplicada, desde el año 2008, a los egresados y titulados de las carreras de Educación Especial, Educación Parvularia, Educación Básica y Educación Media con el objetivo que los resultados permitieran a las instituciones de educación superior contar con un parámetro externo para diagnosticar y monitorear sus avances en los procesos de mejoramiento continuo, y para que los egresados de pedagogía tuvieran un referente respecto a los objetivos esperados durante su formación.

No pretendemos analizar la pertinencia de la efectividad de la prueba en la medición de los conocimientos necesarios para impartir la docencia. Nuestra inquietud es solamente la búsqueda de algún patrón en los resultados relacionado a la asignación de los docentes evaluados a los distintos colegios, particularmente aquellos con niños más vulnerables.

Con este objetivo, utilizamos los datos individuales con los resultados de las pruebas de los años 2009, 2011, 2012 y 2014 y los unimos con la información del censo docente, que permite conocer el establecimiento educacional que emplea al profesor egresado.' Una vez que conocemos el colegio en el cual imparte clases cada egresado que rindió la prueba, clasificamos a los establecimientos según el porcentaje de alumnos prioritarios para el otorgamiento de la Subvención Escolar Preferencial (SEP), lo cual nos da una medida de la vulnerabilidad de los alumnos.

De esta forma, y destacando que este es un análisis descriptivo que no pretende explorar la relación causal, nuestros datos permiten conectar el resultado de la prueba inicia con la vulnerabilidad del colegio en la que los egresados imparten clase. Asi la Figuras 1 y 2 muestran el promedio del Indice SEP del colegio empleador para cada puntaje de las pruebas de conocimientos escrito y disciplinarios, respectivamente. Note en la Figura 1 que el porcentaje de vulnerabilidad del colegio receptor cae abruptamente para los graduados con con puntaje de más del $80 \%$ en la prueba escrita. En el caso de la prueba de conocimientos disciplinarios, la Figura 2 muestra una relación inversa y monótona entre puntaje y vulnerabilidad del colegio.

A pesar de las limitaciones del análisis descrito más arriba, el resultado no hace sino reafirmar algo que no era difícil de sospechar. Nuestros alumnos más vulnerables no reciben su enseñanza por parte de nuestros mejores profesores, sino mas bien lo contrario. Las causas de estos patrones de comportamiento pueden ser varias, desde salarios inferiores en los colegios más vulnerables hasta la menor predisposición de los mejores docentes a enseñar a niños que traen menor bagaje educativo desde la casa. El hecho es que si, independientemente de la causa, a los niños que potencialmente tienen mayor dificultad de aprendizaje los enfrentamos a los docentes con más dificultades para expresarse por escrito o para transmitir el conocimientos, la combinación es fatal. Cabe destacar que en los últimos años se implementó una política tendiente a corregir estas eficiencias, Ilamada "Beca de Vocación de Profesor", que premia a alumnos de pedagogía con alto puntaje PSU, con la condición de que una vez graduados enseñen en colegios municipales o subvencionados. Aunque todavía es muy pronto para evaluar si esta política tiene algún impacto, parecería ir en la dirección apropiada.

Es muy probable que los egresados en pedagogía que no sacaron buenos puntajes en la prueba Inicia hayan sufrido de la deficiencia de sus colegios de origen, o estudiaron en alguna institución cuya calidad pueda cuestionarse. Si bien eso es algo que debe corregirse, el problema que esto genera va más allá de la calidad de la educación superior. Porque, aunque dichos jóvenes se hayan preparado (como pueden) para enseñarle a los más chicos y es legitimo que tengan esa aspiración, el problema se ve como insoluble cuando las deficiencias formativas se transmiten de generación en generación.

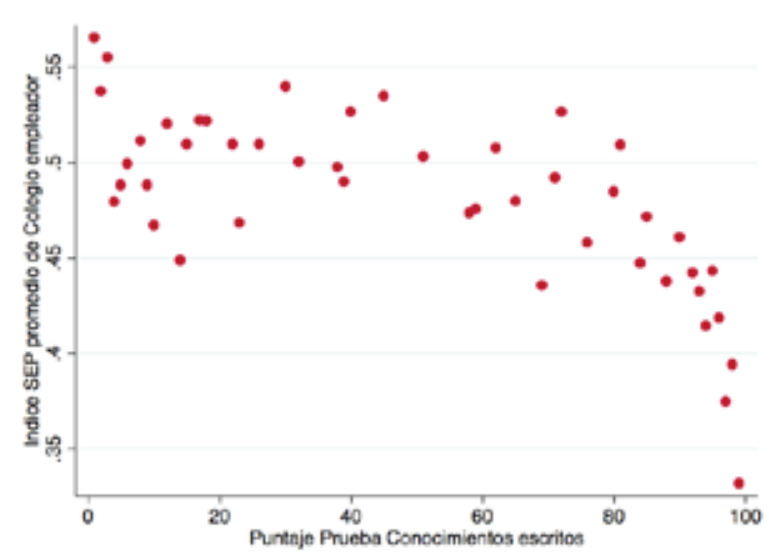

Figura 1: Puntaje prueba conocimientos escritos e Índice SEP del colegio empleador.

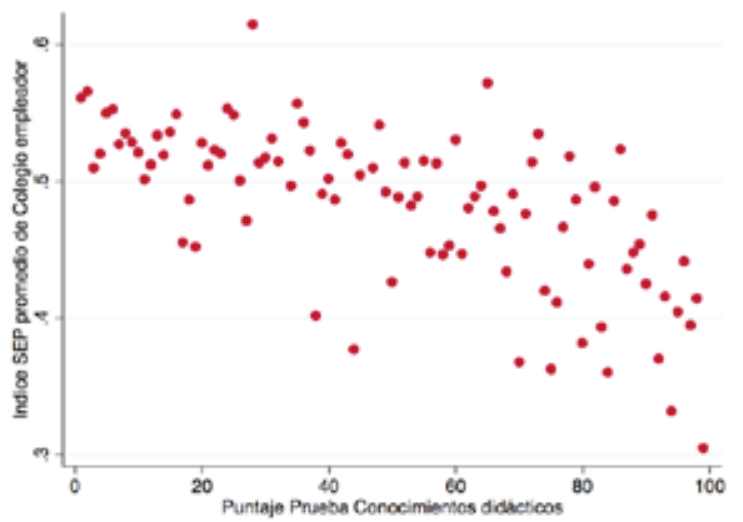

Figura 2: Puntaje prueba conocimientos disciplinarios e Índice SEP del colegio empleador 